\title{
Applying science as a tool for dairy farmers
}

\author{
J. SAVAGE ${ }^{1}$ and C. LEWIS ${ }^{2}$ \\ ${ }^{1}$ Macfarlane Rural Business Ltd, P.O. Box 418, Ashburton \\ ${ }^{2}$ Baker and Associates, P.O. Box 900, Masterton \\ Jeremy@mrbusiness.co.nz
}

\begin{abstract}
Dairy Systems Monitoring (DSM) was developed out of response from dairy farmers for a benchmarking tool that made fair and equitable comparisons between farms. This benchmarking system is used by the clients to improve their productivity and profitability.

The dairy farm simulation model UDDER is used to simulate the farm system. The input information is milk production from fencepost, and monthly data from the farm, including, areas, stock numbers, supplements, crops and nitrogen $(\mathrm{N})$. The model is then calibrated to simulate the farms production, revised and validated monthly.
\end{abstract}

There has been a successful uptake of this program. Currently 50 farms are involved. Dairy Systems Monitoring has generated change in the systems of participating farmers. Dairy Systems Monitoring has proven to be an effective tool to demonstrate the impact of a range of new technologies on farm systems.

The tool is used on an ongoing basis to simulate and compare different operating strategies. It has the ability for clients to compare themselves to simular farms.

A key benchmark that is analysed is the feed harvested. For every additional 1 tonne of dry matter (DM) harvested, the gross margin (GM) increases by $\$ 339 /$ ha. The question this poses for participants is "how do we harvest more pasture"? Is it by growing more pasture, or improving management to harvest more of the existing pasture growth?

Dairy Systems Monitoring is an effective extension tool to highlight the impact of new technologies or management practices on the client's farm program.

Keywords: benchmarking, dairy farm programmes, feed harvested, gross margins, UDDER model

\section{Background}

Dairy Systems Monitoring was developed by Chris Lewis, Baker \& Associates, and recently Jeremy Savage, Macfarlane Rural Business as a result of growing demand from dairy farmers for a benchmarking tool that makes fair and equitable comparisons between farms.

This benchmarking system is used by consultants and their clients to improve the clients productivity and profitability. The information in the benchmarking is shared between clients with an open book policy and Chatham house rules.

The consultant focus is on the use of good science to accurately model farm practices. The results from the modelling are benchmarked with their peers in the industry, and used to advise clients with confidence.

\section{Approach}

The dairy farm simulation model UDDER is used to model the farm system. The input information is milk production from Fencepost, and monthly data from the farm that includes areas, stock numbers, supplements, crops, $\mathrm{N}$ etc. The UDDER model is adjusted to simulate the farm for the previous month. This accurately portrays year to date results for the season to date. The model then forecasts the balance of the season on the basis of the parameters that have been entered in the model at the start of the season. In case of extreme changes, for example in drought conditions, the parameters are modified to the current situation.

Data base software has been written. This sorts the raw data from UDDER into industry standard benchmarks. These benchmarks are included in a range of output and results provided to the farmer:

- Monthly farm summary, how the farm has performed in the past month relative to the revised target, and what is expected to happen in the next month.

- Benchmark report, a summary of the key industry benchmarks, using relevant data from the previous month and forecasts for the season.

- A ranking of the farm relative to their peers on Key Perfomance Indicators.

- Graphs and individual commentary from the consultant which farmers respond well to.

\section{Gross Margin}

A key benchmark used for DSM is the GM/ha, which represents the profitability of the farm system. The gross marginal income (GMI) is presented in Table 1.

All income and expenditure are based on the current season's prices for the region. All farms have the same prices for income and expenditure. This is essential to ensure that we compare the profitability of the farm systems, not the ability of the farmer to purchase products at competitive prices.

\section{Results}

The results illustrated are from the 2003/2004 season, which have been supported by the $2004 / 2005$ as discussed. 
Table 1 Method of calculating GMI.

\begin{tabular}{|c|c|c|c|c|}
\hline & Less & Less & Less & Equals \\
\hline Gross income & $\begin{array}{l}\text { Fixed per cow } \\
\text { expenditure }\end{array}$ & $\begin{array}{l}\text { Variable } \\
\text { expenditure }\end{array}$ & \multirow{9}{*}{$\begin{array}{l}\text { Fixed farm } \\
\text { expenditure } \\
\text { Irrigation }\end{array}$} & \multirow[t]{9}{*}{$\begin{array}{l}\text { Gross marginal } \\
\text { income }\end{array}$} \\
\hline Milk income & Labour & Supplement & & \\
\hline Cull cow & (Marginal cost) & costs & & \\
\hline income & Breeding & Grazing costs & & \\
\hline Bobby calf & Animal health & Nitrogen & & \\
\hline income & $\begin{array}{l}\text { Replacement } \\
\text { costs }\end{array}$ & Cropping & & \\
\hline & Shed costs & & & \\
\hline & Interest/ & & & \\
\hline & & & & \\
\hline
\end{tabular}

\section{(b) Pasture renovation}

Dairy Systems Monitoring is an effective tool in assessing returns from regrassing. The key to success is obtaining the appropriate data on improvements in yield from new pastures over time. This is a systems approach where the time involved in regrassing and feed lost needs to be included in the model.

\section{(c) Nitrogen use}

Most participants are using $200-230 \mathrm{~kg}$

\section{Pasture harvested vs gross margin per hectare}

Pasture harvested is the feed that is consumed by the cows. For every additional $1 \mathrm{t} \mathrm{DM}$ harvested/ha, the GM increases by $\$ 339 /$ ha (Figure 1). For the 2004/2005 season with 25 farms, GM increases by $\$ 304 /$ ha for every additional $t \mathrm{DM}$ harvested $\left(\mathrm{R}^{2}=0.65\right)$.

Dexcel's analysis of the 2002 Westpac Fonterra dairy excellence awards contestants showed "strong evidence that pasture eaten/ha is a feature of a profitable New Zealand dairy farm". "For every extra tonne of pasture DM eaten expect an additional \$200/ha profit (economic farm surplus (EFS)/ha)" (Glassey 2005).

Dexcel Profit Watch Data from 117 Taranaki farms illustrated that high EFS farms $(>\$ 2000 /$ ha) were consuming $15.8 \mathrm{t} \mathrm{DM} /$ ha while the lower EFS farms ( $<\$ 1200 /$ ha) consumed 11.5 t DM/ha (McGrath 1997).

This relationship focuses the participants on increasing feed harvested. It raises the question of how do we harvest more pasture? Is it by growing more pasture, or improving management to harvest more of the existing pasture growth?

\section{Increase pasture grown}

\section{(a) Irrigation}

Figure 1 illustrates the changing returns from a wide range of feed harvested. For the Canterbury group which has been illustrated, these farms can be grouped by the capacity and efficiency of their irrigation system.

The farms in the 7.5 to $10.5 \mathrm{t} \mathrm{DM}$ harvested/ha range are $100 \%$ border-dyked, with one poorly irrigated spray irrigated farm $(0.31 \mathrm{l} / \mathrm{sec} / \mathrm{ha})$.

Farms in the range of 10.5 to $13 \mathrm{t} \mathrm{DM} /$ ha are irrigated by a combination of spray and border-dyke irrigation, with $0.50-0.55 \mathrm{l} / \mathrm{s} / \mathrm{ha}$.

Farms harvesting in excess of $13 \mathrm{tDM} /$ ha are centre pivot farms and very well spray irrigated farms.

Participants have used these results to assess the returns from improving the irrigation systems to grow more grass. This is determined by the improvement in GMI with improved productivity less additional capital and running costs of the irrigation system. nitrogen $(\mathrm{N}) / \mathrm{ha}$ and are reluctant to increase $\mathrm{N}$ use further. Modelling of feed demand and supply ensures that the $\mathrm{N}$ use occurs when the need is greatest.

\section{Increasing pasture harvested}

Improved management of pastures has proven to be the most effective method to increase pasture harvested. Focussing on round lengths, grazing windows and residuals has resulted in significant gains in feed harvested as presented by Lincoln University Dairy Farm (LUDF) over the past two seasons at public field days.

For the 2004/2005 season, a number of farms have adopted the grazing regime of intensive residual and round length control. These farmers can compare themselves with the LUDF who participate in DSM. This has been rewarding for some farmers, and has helped others to highlight where their farm program encountered problems.

Milksolids (MS) production, on a per cow basis is a significant driver to increase feed harvested for the season. Cows which peak higher in the spring will have a higher potential feed demand for the balance of the season as their potential MS yield curve is higher for the balance of the season. This increased demand drives up the feed harvested relative to poorer producing cows at the same stocking rate (SR).

\section{Stocking rate}

Stocking rate should balance the dual objectives of generous feeding to achieve high levels of efficiency of MS production/cow and underfeeding to achieve high levels of pasture utilisation to meet the overall objective of optimising farm profitability (Penno 2000).

Dairy Systems Monitoring analysis highlights the impact of SR on productivity and profitability as shown in Figure 2.

Figure 2 illustrates that profitability increases with SR. This relationship was repeated in the 2004/2005 season $\left(R^{2}=0.55\right)$. Designing and implementing a farm programme which matches the feed supply to the demand can influence total feed harvested for the 
Figure 1 The effect of pasture harvested on $\mathrm{GM} / \mathrm{ha}$.

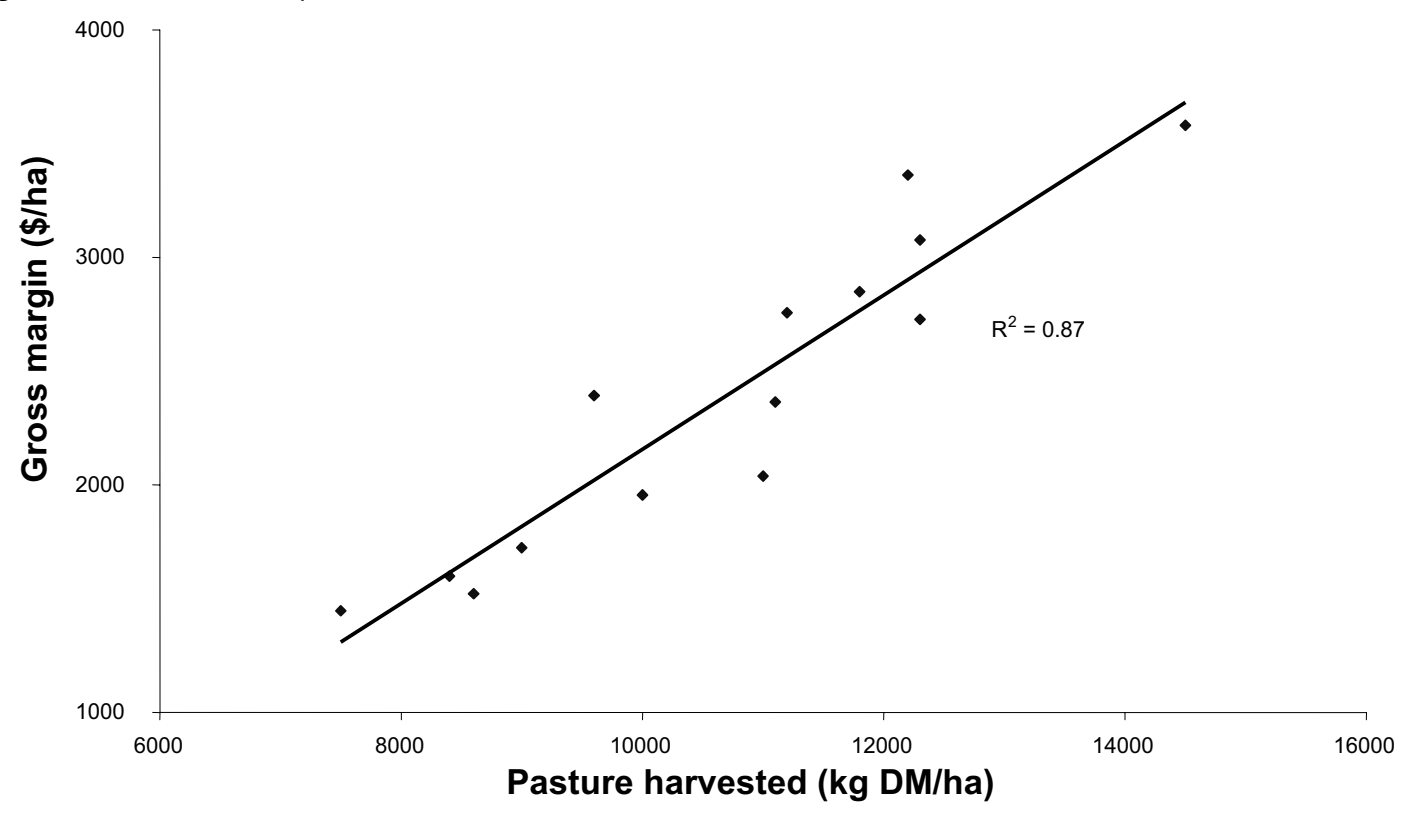

Figure 2 The effect of stocking rate on $\mathrm{GM} / \mathrm{ha}$.

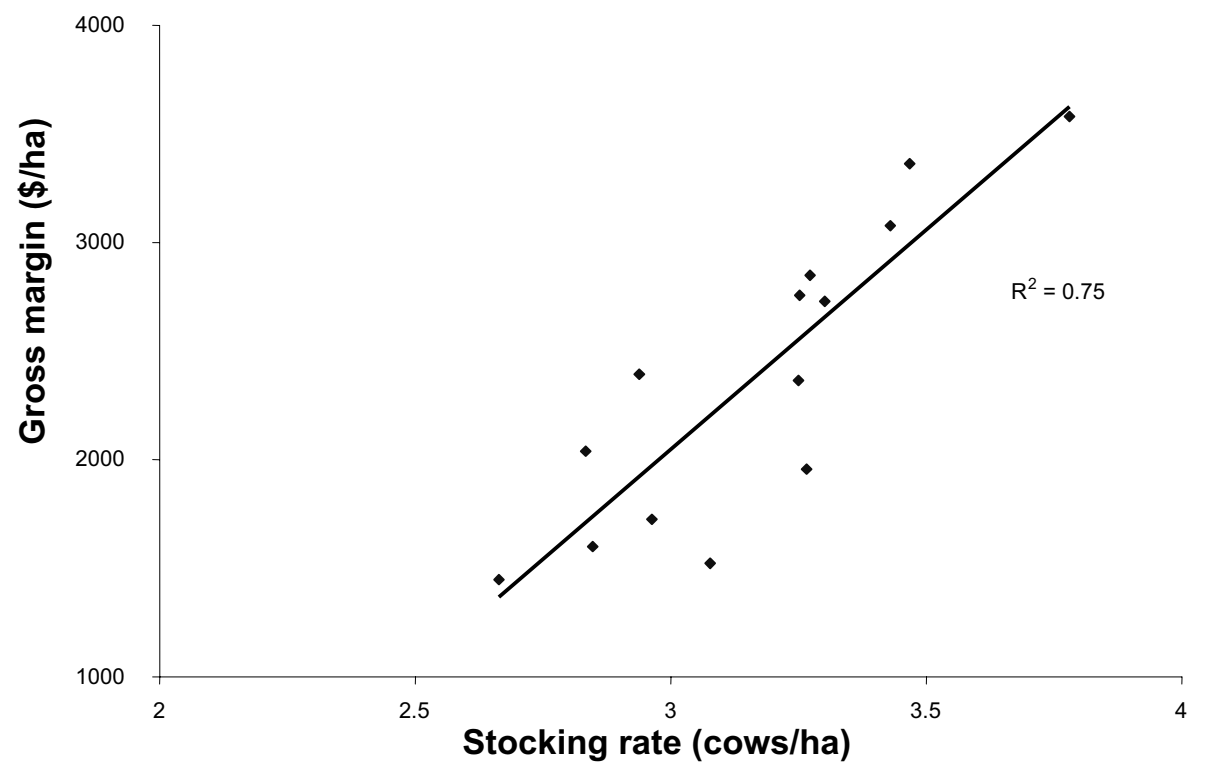

season. Selecting the appropriate SR is a crucial factor. This SR needs to ensure that the cows can express their MS production potential for the season, while having enough mouths/ha to harvest as much feed as possible.

Care must be taken when applying this relationship to farms, as most SRs are based on several years of planning and intuition from the farmers involved. There are a number of farms that fall well below the line. These farms have a range of inefficiencies in the production system that results in them underperforming relative to their SR. In many cases, for these poor performing farms, their SR is too high. A r esult of a too higher SR is that too much feed is partitioned to maintaining the cows rather than milk production. A positive change in 
Figure 3 The effect of supplements fed/cow on $\mathrm{GM} / \mathrm{ha}$.

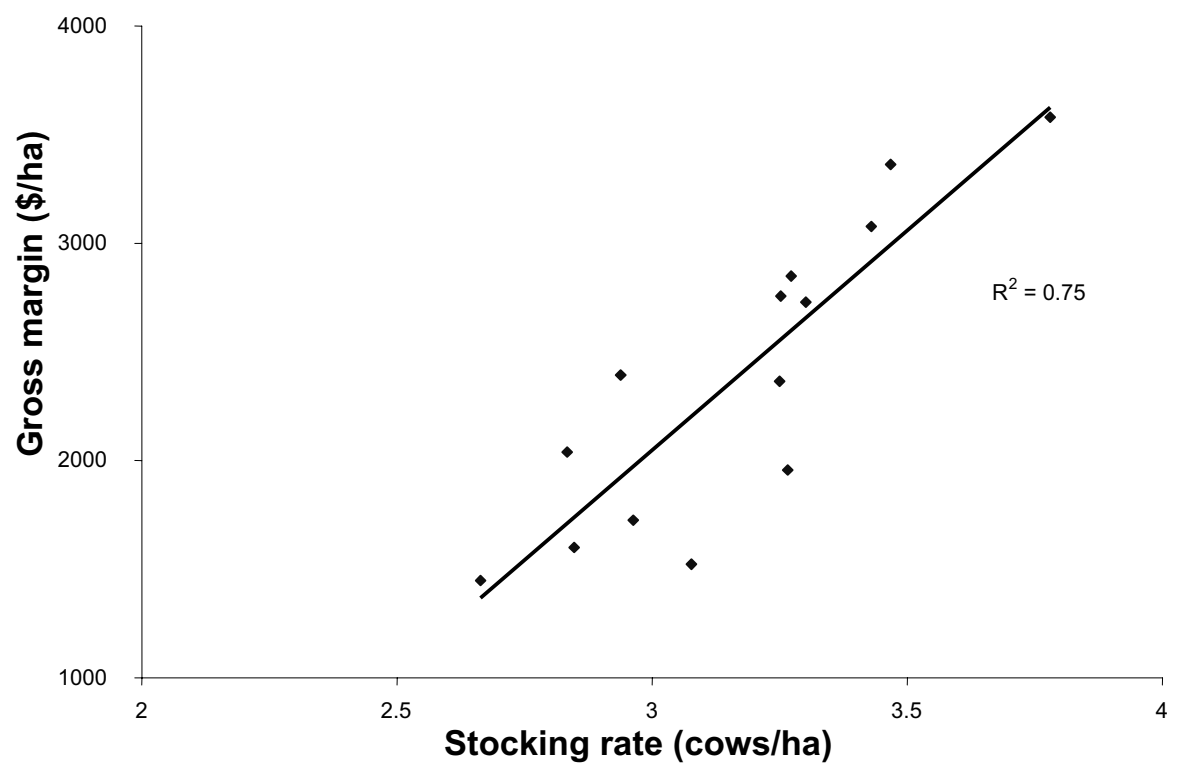

Figure 4 The effect of milking days/ha on GM/ha.

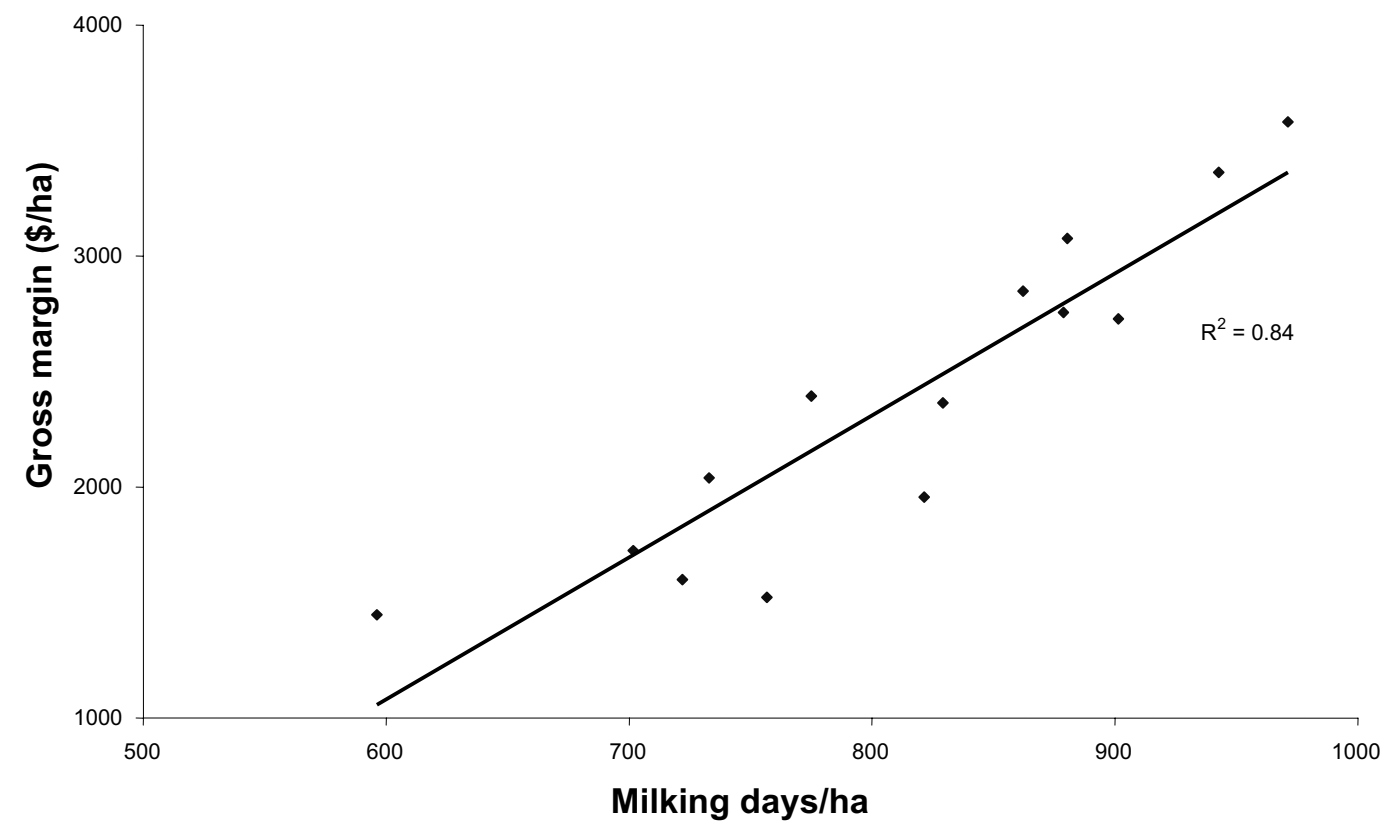

profitability is likely to be achieved by decreasing the SR and achieving higher per cow performance.

\section{Supplementation}

As illustrated in Figure 3, the amount of supplement used/cow has little impact on the profitability. Observation over three years suggests the type of supplements used also has little impact on the profitability. The profitability of the system is dependant on the farmer's management of the cows and farm programme to turn supplements into milk.

Participants use the DSM data and UDDER model intensively to ensure that their management will result in profitable returns from supplementation. 
The first decision is when using supplements is how long is the response is required for? A short term response reflects what will be the in vat over the next week. A medium term response highlights the impact of supplements on the balance of the season and the subsequent season. This includes the impact on cow condition and pasture cover over the medium term. The long term response affects the sustainability of the
Stocking rate plays a significant role in the milking days/ha. For most DSM participants, the appropriate $\mathrm{SR}$, in combination with the longest average cow lactation length will maximise the farms milking days/ ha. This increases the profitability as shown in Figure 4. This graph highlights some farmers who are aiming for high milking days/ha but are not achieving the profitability/ha.

Figure 5 Pasture covers over the season for three groups of farms.

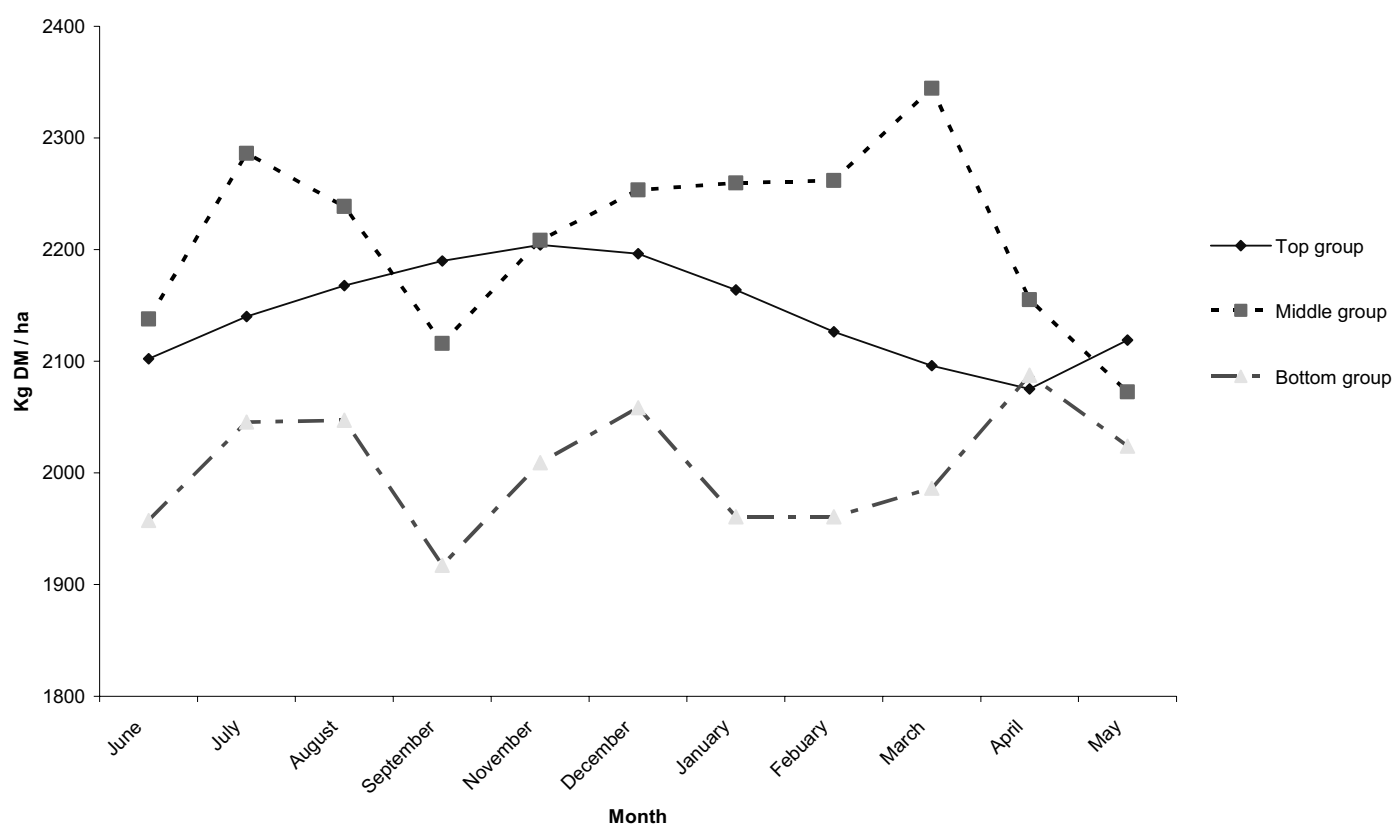

business, this includes impacts on herd health, fertility, environment and capital demands of plant and supply company shares. Participants in DSM develop a sound understanding of the big picture from using supplements in their business.

Consultants work with farmers to develop operational guidelines to ensure that fast, effective decisions can be made. These guidelines typically are based on trigger points on round lengths and pre-grazing pasture levels. Trigger points are developed for timing of silage making on the dairy platform.

\section{Milking days}

Milking days/ha is determined by the SR multiplied by the average lactation length of the herd. Lactation length /cow is influenced by calving date, calving spread, the ability to retain cows in milk for the season, and the average drying off date. Culling due to summer dry spells, high death rates and early culls due to poor cow quality all shorten the average lactation length. Dairy Systems Monitoring participants focus on extending the lactation for as long as possible.

\section{The grazing window}

Figure 5 illustrates the average pasture cover of 3 groups of farms which were ranked in terms of their profitability as presented in Table 1.

The high group stayed in the ideal grazing window for the whole season, i.e. $2100-2200 \mathrm{~kg} \mathrm{DM} / \mathrm{ha}$. For most of the season the middle group had a similar amount of feed on-farm, however they had a short fall during the spring which limited cow intakes and production, this was followed by an excess of feed which had a detrimental affect on feed quality and subsequent feed quality for the season.

The high group's grazing and feed management is based on staying within the optimal grazing window.

Table 1 Gross margin/ha ranked in three groups of farms.

\begin{tabular}{lcc}
\hline Ranking & GM/ha & kg MS/cow \\
\hline High & $\$ 3428$ & 409 \\
Medium & $\$ 2421$ & 377 \\
Low & $\$ 1662$ & 336 \\
\hline
\end{tabular}


Table 2 Monitoring of improvements in profitability and productivity on a case study farm over three seasons.

\begin{tabular}{lccc}
\hline & $2002 / 2003$ & $2003 / 2004$ & $2004 / 2005$ \\
\hline Cows & 500 & 540 & 554 \\
Area (ha) & 165 & 165 & 165 \\
Total production (kg MS) & 194775 & 215198 & 221746 \\
Production (kg MS/cow) & 390 & 399 & 401 \\
Supplements (kg DM/cow) & 1212 & 526 & 356 \\
Feed harvested (t DM/ha) & 10.1 & 12.3 & 13.1 \\
GM (\$/ha) & 1776 & 2616 & 2904 \\
\hline
\end{tabular}

When feed cover is heading below $2100 \mathrm{~kg} \mathrm{DM} / \mathrm{ha}$, the farmer reacts by feeding supplements and applying $\mathrm{N}$. When the cover is likely to exceed the grazing window of $2200 \mathrm{~kg} \mathrm{DM} / \mathrm{ha}$, the management response is to harvest this surplus for silage. When interviewing the top farmers, it was evident that everyone in this group was monitoring paddocks which were at least one week from grazing to assess their covers relative to the grazing window. This monitoring w as carried out at least twice per week. All of these farmers have a sound under standing of the grazing window requirements for their farm.

Grazing round length management is essential to ensure that cow's intakes are maximised while maintaining residuals to maintain quality. The length of time between grazing is essential for quality, with the highest performers at 18-22 day grazing intervals for most of the season, mid-spring to early-autumn.

\section{Case study}

This case study is on a farm which had been converted to dairy farming for the 1999/2000 season. It was an unprofitable farm that needed to generate positive profits quickly to pay for the costs of conversion. This client is an avid user of DSM and uses the programme in detail to improve profitability.

This participant has significantly increased productivity and profitability. Milksolids production over the three years has increased by $13 \%$. At a standardised $\$ 4 / \mathrm{kg}$ MS payout, profitability has increased by $63 \%$. The increase in profitability has been due to improvements in feed conversion efficiencies rather than total productivity.

Feed harvested has increased by 2 t DM/ha. Regrassing and improved management of irrigation and $\mathrm{N}$ use has increased the pasture quality grown on the property. This has been complimented by an increase in the SR and improved pasture management.

Supplement use has dropped significantly. The incr ease in feed grown and harvested/ha has dropped the necessity for supplements. During peak lactation, milk production often drops with high supplement use because the quality of supplements is often lower than grass. The focus of management is to minimise supplement use, especially in the early spring. This has been achieved by off-farm grazing and calving spread.

The strong focus on feed quality has helped increased the per cow milk production. This result was achieved by grazing management focusing on maintaining residuals of $1500 \mathrm{~kg} \mathrm{DM} / \mathrm{ha}$ and round lengths not exceeding 24 days during the spring and summer months. Supplement quality is paramount and are used sparingly.

\section{Conclusions}

Adoption of DSM has a positive impact on the 50 participating businesses. Dairy Systems Monitoring helps participants develop a greater understanding of their farm programs and systems, especially the key drivers for productivity and profitability. The farm's information is presented in terms farmers can understand. Dairy Systems Monitoring has encouraged positive change in the farm systems of participating farmers to improve their profitability as outlined in a case study.

Dairy Systems Monitoring and the UDDER model has proven to be a very good diary, recording the historic events on their property. The impact of these decisions and events are illustrated on the balance of the season by UDDER. It highlights both the mistakes and successes of management.

Many of the benchmark comparisons analysed agree with existing research on farm systems. The farmers have ownership of the results, because they are active participants. Most tend to take longer to ensure that they understand the data, the associated science and the effects on their business.

\section{References}

Glassey, C. 2005. Pasture eaten per hectare - a strong driver of profit. Dexcel Link, Autumn Edition.

McGrath, J. 1997. Farming for high profit. Focus on profitability. Proceedings of the Ruakura Farmers' Conference 49: 20-29.

Penno, J. 2001. Stocking rate for optimum profit. The $4 \%$ performance challenge. Dexcel field days. 